\title{
MJN PERCEIVEd BARRIERS AND MOTIVATING FACTORS INFLUENCING RESEARCH PRODUCTIVITY AMONG NURSING AND ALLIED HEALTH PROFESSIONALS TRAINERS
}

\author{
Sunita Shanmugam*, Norhaniza Zakaria, Munirah Ismail, Pangie Bakit, Norhidayah Mat Diah \\ Ministry of Health Malaysia, Institute for Health Management, Malaysia \\ *Corresponding Author's Email: drsunita26@yahoo.com
}

\begin{abstract}
Introduction: Ministry of Health $(\mathrm{MOH})$ Malaysia colleges, offer diploma and advanced diploma programmes for nursing, assistant medical officer and other allied health personnel. As academic institutions, the trainers are encouraged to participate and enhance the colleges' research productivity. The aim of this study is to explore the perceived barriers and motivation factors for research in $\mathrm{MOH}$ colleges. Method: A qualitative research design was conducted among $\mathrm{MOH}$ colleges trainers. Semi structured questions were used in 11 Focus Group Discussion (FGD) and 13 In-Depth Interview (IDI) among 98 respondents from seven MOH colleges. Thematic analysis was used to identify emerging themes from the interviews. Results: Three institutional factors motivate engagement in research: key performance indicator, research support and research skills. Majority of respondents were aware of the importance of research, but their research productivity is low due to perceived barriers related to human resource, research material, technical and funding support. Conclusion: The findings are useful in understanding research motivation as well as ascertain barriers that can be overcome through better support and recognition. Such understanding will help improve the policy for research across the colleges.
\end{abstract}

Keywords: Barriers, Motivation, Research, Nursing, Allied Health

\section{INTRODUCTION}

Research is considered the main structure of sustainable social, cultural, and economic development of a nation and promotes self-sufficiency and independence of nation (Azarmi et al., 2018). Li, Millwater \& Hudson (2008) stated that the building of the nation's capacity to generate knowledge, is of importance to countries all over the world. Major part of research activities in most countries are conducted by faculty members of universities and research institutes. Capacity building in research is of grave concern especially since WHO recommended all nurses should hold a degree rather than diploma in nursing, shifting the focus of nursing education to university level education (Boyd et al., 2009). According to Frantz (2012), "research capacity development is a global issue faced by all health professionals as it aims to enhance a profession through providing evidence for intervention strategies and thus assist in improving the quality of the healthcare delivered". Research capacity building has not only caused significant changes in higher education institutions, but it has also placed pressure to publish on academic staff, especially new lecturers who don't have enough experience in research (Smith \& Boyd, 2012).

A study done in Vietnam showed that researchers are dissatisfied with the lack of time, limited opportunity to disseminate results, as well as unsuitable trainings, tend to demotivate educators to conduct research (Hiep, 2006). A survey carried out amongst 997 students of Australian and New Zealand College of Anesthetists identified that lack of time was the major barrier that stopped research activities, followed closely by funding constraints and lack of exposure and training in research activities (Gurunathan, Berry \& Way, 2016). In Malaysia, a previous study done on 467 specialists in government hospitals in the northern states, traced barriers to research as lack of funding, inadequate guidance from mentors, lack of access to research 
expertise, software and statistical analysis (Choo \& Pung, 2017).

The Ministry of Health Malaysia $(\mathrm{MOH})$ encourages research culture amongst the staff to meet the evolving challenges in the country. However, Malaysia's expenditure on research and development was only $1.1 \%$ of the Gross Domestic Product (GDP) (Khazanah Institute, 2018). Understanding the strength and weaknesses of the existing research activities and identifying the barriers in conducting research is the first step to increase research capacity building within the nation, by the relevant stakeholders. Although there have been numerous studies regarding barriers in conducting research and research activities carried out, there is no study focusing on faculty members of nursing and allied health colleges in Ministry of Health Malaysia. The aim of this study is to explore the barriers and motivational factors in research productivity among nursing and allied health professionals in $\mathrm{MOH}$ colleges.

\section{METHODOLOGY}

A qualitative method was used to explore the barriers and motivational factors in conducting research among faculty members of $\mathrm{MOH}$ colleges as it allows researchers to hear the participants' own perspectives (Creswell, 2009). Faculty members or trainers from three nursing colleges and four KSKB (Kolej Sains Kesihatan Bersekutu or Allied Health Sciences College) were selected to be part of Focus Group Discussions (FGDs). The directors or deputy directors of the colleges were chosen for In-depth Interviews (IDI). Two FGDs were conducted among faculty members in KSKB based on their profession for example, nursing, assistant medical officer and allied health professionals. Respondents were chosen through a purposive sampling. Each FGD consists of seven to eight respondents.

The study was conducted for a duration of 8 months from April 2016 to December 2016. A semi structured open-ended questions was used to guide the interviews. Four main questions (as shown in Table 1 below) were developed based on a group of expert panel experience in research. The questions were pre tested in a preliminary round with a group of faculty members. Interviews were carried out until data saturation was achieved, marked by no more new themes emerging from discussions and interviews.
Table 1: Interview questions

\begin{tabular}{|l|l|}
\hline No & Interview questions \\
\hline 1. & $\begin{array}{l}\text { What do you think about the current capacity in } \\
\text { research and development in the colleges? }\end{array}$ \\
\hline 2. & $\begin{array}{l}\text { What are the issues and challenges faced by the } \\
\text { faculty members in conducting research? }\end{array}$ \\
\hline 3 & What are the benef its to those who are involved in research? \\
\hline 4. & $\begin{array}{l}\text { What needs to be done to develop the capacity and } \\
\text { capability of faculty members in research? }\end{array}$ \\
\hline
\end{tabular}

The aim of this study was explained in detail to all the respondents at the beginning of the FDGs and IDIs. Complete confidentiality and non-disclosure of their personal information was assured. All sessions were facilitated by experienced researchers who are not directly involved with the respondents' working practice. Interviews lasted between 45 and 60 minutes and audio recorded. All the interviews (FGDs and IDIs) were transcribed verbatim and verified again with the corresponding audio recordings for veracity by four of the researchers. Content analysis was carried out inductively through open coding, creating categories and abstraction. The verified transcripts were read independently among the research team members and summarised using headings to describe the contents and later came in with common consensus. Similar headings were grouped into higher order categories in order to reduce the number of categories (Elo \& Kyngas, 2008). Each category and subcategory represent the barriers and motivation raised by the respondents.

The ethical issues related to this study were the anonymity and confidentiality of the respondents. Written consent was obtained from the respondents at the commencement of each FGD or IDI. Ethical approval for the study was granted by Medical Research and Ethics Committee (MREC), Ministry of Health Malaysia.

\section{RESULTS}

A total of 11 FGD sessions and 13 IDIs with relevant stakeholders were conducted.The demographic characteristics of 87 participants who were involved in the FGD are shown below.

\section{Table 2: Demographic of FGD respondents}

\begin{tabular}{|c|c|}
\hline Demographic & $\mathrm{n}(\%)$ \\
\hline $\begin{aligned} & \text { 1. Gender } \\
& \text { - } \text { Male } \\
& \text { - } \text { Female } \\
&\end{aligned}$ & $\begin{array}{l}21(24.1 \%) \\
66(75.9 \%)\end{array}$ \\
\hline $\begin{array}{l}\text { 2. Year of experience in teaching } \\
\text { - Less than } 5 \text { years } \\
\text { - } 5-10 \text { years } \\
\text { - More than } 10 \text { years }\end{array}$ & $\begin{array}{l}29(33.3 \%) \\
22(25.3 \%) \\
36(41.4 \%)\end{array}$ \\
\hline $\begin{array}{l}\text { 3. College } \\
\text { - Nursing College } \\
\text { - Allied Health Sciences College (KSKB) }\end{array}$ & $\begin{array}{l}24(27.6 \%) \\
63(72.4 \%)\end{array}$ \\
\hline $\begin{array}{l}\text { 4. Programme } \\
\text { - Nursing } \\
\text { - Other Allied Health Sciences (non-nursing) }\end{array}$ & $\begin{array}{l}60(68.9 \%) \\
27(31.1 \%)\end{array}$ \\
\hline
\end{tabular}


Themes and sub-themes explored by the research team which emerged from the data collected are shown in Tables 3 and 4 .

\section{Perceived motivating factors on current research productivity}

Table 3: Perceived motivating factors on current research productivity

\begin{tabular}{|l|l|}
\hline \multicolumn{1}{|c|}{ Theme } & \multicolumn{1}{c|}{ Sub-theme } \\
\hline \multirow{2}{*}{ Key Performance Indicator } & Level of Responsibility \\
\cline { 2 - 2 } & Reward system \\
\hline \multirow{4}{*}{ Research Support } & Top management commitment \\
\cline { 2 - 2 } & Collaboration with experience researcher \\
\cline { 2 - 2 } & Providing guidance for students \\
\cline { 2 - 2 } & Dissemination of research findings \\
\hline \multirow{2}{*}{ Research Skill } & Confidence and motivation \\
\cline { 2 - 2 } & Level of education \\
\hline
\end{tabular}

\section{Key Performance Indicator}

Involvement in research is not required as part of individual key performance indicator (KPI) but rather as a collective KPI which is monitored at college level. Conducting research is not compulsory, though the trainers are highly encouraged to take up research projects. Some colleges started with one research project per year which is included in the college KPI.

"...Research is a requirement by the Training Management Division, so once a year we undertake one research project." (Trainer A)

"...But the KPI is per college, not per trainer..." (Trainer B)

“...To achieve the college's KPI for research under the Assistant Medical Officer programme, a group of faculty members under the programme will be selected to carryout research project..." (Trainer C)

Even though research is highlighted as capacity building for educational staff or trainer, however no special incentives are rewarded to those who conduct research. Their counter-parts in universities on the other hand are promoted based on their performance in research and academic publication.

"Normally there isn't any incentive. Actually, selfsatisfaction that you will come once you completed your research" (Director A)

“.. It is not easy to do research. So, need to have some difference, in term of giving them some incentives..."

\section{(Trainer D)}

\section{Research Support}

The respondents believed that support and guidance either from clinicians, experienced researchers and top management is important for them to move forward in their research activities.

“... Training Management Division organised a few workshops and courses especially for the trainers who are involved in research..." (Deputy Director B)

“... This few years, we are trying to encourage them. I bring in an external lecturer to give the input on research methodology, all this thing. We are starting to do simple research..." (Director $C$ )

"...We always collaborate with our hospital. Especially with the specialists... And then the tutors, the senior tutors become the panel for the assessment. So, I think it's not the issue of research..." (Director D)

“...So here we got the manpower to teach, doing research, in fact we can get some people to help us, for instance the doctor, the clinician there, he is very good, he is keen you know. So, we are very lucky because we can get consultancy..." (Deputy Director E)

As part of the requirement for diploma programme, students of most colleges must prepare research proposal or case study. The trainers are responsible to oversee and guide the students.

"...We all supervise the research component. Today, they have gone until linear regression. They understand that level, so we feel proud of the students..." (Trainer D)

The respondents have varying experience about research dissemination. Some of them were unsure how to present research findings and means to publish.

“...Where do I publish my article, I don't see our research findings being used for any purpose or as a reference..." (Trainer E)

Some respondents claimed they encountered difficulties in disseminating research output and impact of the research. However, there are respondents who took the initiative to present their research findings at national or international conferences.

“...We do participate in the CRC National Research Day, we ask them to come in to participate and we do organise some international conference to expose them 
to all the research presentation, all this thing that will help them to gain the confidence..." (Director C)

\section{Research skills}

Some respondents feel that they are confident and motivated to conduct research project based on their experience during their undergraduate or postgraduate years. Respondents who have completed masters or $\mathrm{PhD}$ programmes have more experience in research as compared to those who did not.

"...The tutor, they actually learn in their degree programme. Some of them, they only write research proposal. They didn't go through the research project all by the proper research. So, some of them may not have confidence to do it... " Director C)

“...I think doctor, capability, I think all trainers got expose basically to do a research. I think it shouldn't be anyproblems..." (Trainer F)

"...Looking at the background of all trainers especially for Medical Assistant programme, they already been expose to research during their diploma year. And during undergraduate year/degree level, they have a subject on research. So, for them to carry out research, there should be no problem..." (Trainer G)

...I personally feel that if you have a master's degree, you will be more geared towards research. You will have that, you know that will be charismatic enough and have that level of confidence compared to you just having basic degree..." (Trainer M)

\section{Perceived barriers to Research Productivity}

A multitude of resources are required to achieve good research outcomes. These include manpower, time, access to journals, availability of data analysis tools, funds amongst others.

Table 4: Perceived barriers to Research Productivity

\begin{tabular}{|l|l|}
\hline \multicolumn{1}{r|}{ Global Themes } & \multicolumn{1}{c|}{ Subthemes } \\
\hline \multirow{2}{*}{ Human Resource } & High workload \\
\cline { 2 - 2 } & No Protected time \\
\hline \multirow{4}{*}{$\begin{array}{l}\text { Research Material \& } \\
\text { Technical Support }\end{array}$} & $\begin{array}{l}\text { Access to internet/Informative Technology } \\
\text { (IT) support }\end{array}$ \\
\cline { 2 - 2 } & $\begin{array}{l}\text { Access to journal and database } \\
\text { Statistical tools e.g. Statistical Package } \\
\text { for the Social Sciences (SPSS) }\end{array}$ \\
\hline Funding & Research grant \\
\hline
\end{tabular}

\section{Human Resources}

One of the sub-themes identified as a contributing factor is the lack of involvement in research due to time constraints to carry out research. The trainers are burdened with teaching workload and non-academic roles; managing the extra-curricular activities of the students. On top of that, trainers are also tasked with administrative work. All these make it very challenging for the trainers to set aside time for research.

“... to do research, we still have some limitation, our teaching hours is very packed" (Trainer $L$ )

“...Beside our academic activities, we have a lot of co-curricular activity that BPL want us to organise, like we have majlis tilawah. We have choir competition, we have sports, so all this activity requires them to plan out, to be with the students. So that one takes out quite a lot of their time..." (Director D)

"... Because we had visitor from Australia, she went to $C R C$, they are impressed, and they ask how long the protected time is. We like, protected time? So how are you doing research without protected time..." (Trainer $N$ )

\section{Research Material and Technical Support}

Limited access to databases and research materials interferes with the trainer's ability to conduct proper literature review which is one of the major components of a research. The respondents also highlighted their difficulty to access the internet in the college, as some areas had slow internet speed. The trainers also think that availability of analytical software such as Statistical Package for the Social Sciences (SPSS) can further enhance research activity in the college.

"... The WIFI internet we used was very slow, and very limited area can access to the internet..." (Director C)

"... The limitation is that we don't have that, what we call the website for us to go into to get our literature review because last time they give us the one, we try to go in but not many articles we can find. Every time we want to look for this article, we must pay. It is expensive, you see..." (Trainer $P$ )

"...In terms of looking for information, it is very limited, in term of access..." (Trainer $S$ )

"... reference book is limited, journal is limited, there is online journal, the only search one is only through virtual library, and virtual library not much of nursing material that can get..." (Director $C$ )

“... and a lot of programme, if you would like to do a 
research such as a SPSS programme, we don't have, we cannot simply use not original programme..." (Director C)

\section{Funding}

Many of the respondents have misconceptions of research grant application process from the Ministry of Health to conduct their research. Some of the faculty members perceive that it is easier to obtain a research grant if they were in a university.

"... in terms of budget, we don't really have fund for research...” (Trainer $U$ )

"...It is so difficult to secure grant for research, compared to university or institute, just write a proposal, and they will get the grant..." (Trainer T)

\section{DISCUSSION}

This paper reports the findings of a qualitative study on the perception of $\mathrm{MOH}$ colleges' trainers towards research productivity. The findings are important as it will help to understand the current capacity of research productivity, issues and barriers among our faculty members as a step toward improving our $\mathrm{MOH}$ training colleges.

In the study, we identified lack of time as one of the common barriers in conducting research by our trainers. Our finding is consistent with a few other studies carried out in other parts of the world (Jahan et al., 2015; Farzaneh et al., 2016; Ahmed, Boswell \& Lawrie, 2014). About $67 \%$ of radiologist residence surveyed in Canada agreed that their biggest barrier to conducting research is time constraints due to other commitments such as study demands, on-call demands, daily clinical duties and family and social responsibilities (Hames, Patlas \& Duszak, 2018). Dedicated research time was suggested by the faculty members to overcome this barrier. Studies in the past have been carried out to evaluate the benefit of dedicated research time. A minimum of one month was shown to have an impact on research productivity and project completion to foster residence research interest (Hames, Patlas \& Duszak, 2018; Hardman et al., 2013; Bammeke et al., 2015; Jerzak \& Haider 2015; Silcox, Ashbury \& Vandenkerkhof, 2006; Rothberg et al., 2014).

In view of small number of trainers with postgraduate qualification and limited experience conducting research, the research team might not have much guidance or mentor to oversee the research activity. Lack of human resource also includes lack of research mentorship within the faculty. Studies have shown that having in house faculty mentors are critical to the implementation and execution of any research project (Hames, Patlas \& Duszak, 2018; Mok, Probyn \& Finlay, 2016; Durning et al., 2004). Some colleges receive guidance in research from Clinical Research Centers (CRCs) of the affiliated hospitals, but unfortunately there are many colleges that do not receive this type of support. According to Gil et al., (2001) mentorship either from faculty or experienced senior residents, was fundamental in creating a successful research culture among participant of the survey during the annual Medicine Research Days.

The other barrier mentioned by the respondents was lack of access to journals and articles online and also limited internet accessibility, which are essential components of carrying out any research. Students of Ardabil University of Medical Sciences in Iran rated the lack of access to information sources as the highest mean score barrier in research productivity. Another study reported the lack of access to databases as a significant barrier to research (Hemsley-Brown \& Oplatka, 2005).

Financial support in terms of research funding was another barrier mentioned by the respondents. They perceived they do not have means of getting research grants as compared to their peers in the universities where research is part of the KPI. A study conducted in Oman showed one third of the participants felt that one of the main barriers of research was financial support along with financial incentives and research allotted time (Jahan et al., 2015). A qualitative study done among dental faculty members in King Saudi University, Riyadh, showed lack of schemes to fund. This demotivates them to conduct research (Alrahlah, 2016).

In Ministry of Health Malaysia, research grants can be applied and are available through National Institute for Health as the research wing under $\mathrm{MOH}$. Research proposal should be submitted and registered through National Medical Research Register (NMRR). Proposal is then vetted by reviewers and considered for research grant. The negative perception on difficulty of grant can be overpowered with wider dissemination of knowledge on the due process.

Another study found that promotion and salary raise are the main motivation of lecturers to do research (Kho \& Ling, 2017). Financial incentives (in the form of scholarships to present research findings at international conferences), promotion and professional enhancement are strong indicators to build research capacity (Chomsky et al., 2017; Sabzwari, Kauser \& Khuwaja, 
2009). Currently research is not yet made compulsory as part of KPI in MOH colleges as compared to universities who make it part of their lecturer's KPI. Setting research activity as part of KPI then it becomes a driving force for lecturers to publish their research findings. However, in $\mathrm{MOH}$ colleges, research is rather an organizational KPI. Faculty members showing initiative to conduct research, get self-satisfaction which, although may not be fruitful, as it takes up too much of their time. Our respondents feel that incentives in the form of rewards or scholarship and promotions, may increase trainer's motivation to conduct research. In Ireland, a combination of sabbatical leaves, strong research leadership and financial support (incentives and rewards) was able to successfully increase research capacity building in the School of Nursing and Midwifery in Trinity College, Dublin (Begley et al., 2014).

\section{CONCLUSION}

The present study identified the perceived barriers and motivational factors within the $\mathrm{MOH}$ colleges' for the faculty members participating in research activity. A spectrum of factors was identified which effect research productivity, including lack of allotted research time, accessibility to research material, funding and IT support. As research is fundamental for academic excellence, issues and challenges faced by academic staff in the colleges should be eliminated. Areas for improvement is to embed research culture among the faculty members. Another way is by promoting awareness of $\mathrm{MOH}$ research process and paving the way for grant application, technical support, giving allotted research time and incentives through promotions and scholarships.

\section{Ethical Approval Statement}

The ethical issues related to this study were the anonymity and confidentiality of the respondents. Written consent was obtained from the respondents at the commencement of each FGD or IDI. Ethical approval for the study was granted by Medical Research and Ethics Committee (MREC), Ministry of Health Malaysia.

\section{ACKNOWLEDGEMENTS}

The authors would like to thank the Director General of Health, Ministry of Health Malaysia for permission to publish this article. The authors would also like to acknowledge and express our special gratitude to Training division, $\mathrm{MOH}$, college directors, trainers, project members, Prof Dr. Kathijah Lim and Datin Dr. Noriah Bidin for their contribution.

\section{REFERENCES}

Ahmed, M., Boswell, S. \& Lawrie, C. (2014). Knowledge, Attitude and Barriers Towards Research in The National Health Service (NHS). Archives of Disease in Childhood, 99(Supp12), A1-A620.

Alrahlah, A.A. (2016). The impact of motivational factors on research productivity of dental faculty members: A qualitative study. Journal of Taibah University Medical Sciences, 11(5), pp 448-455.

Azarmi, S., Aliyari, S., Zareian, A. \& Sharififar, S., (2018). Research Barriers from the Viewpoints of Faculty Members of a Military University of Medical Sciences. Journal of Archives in Military Medicine, 6(2): e66867.

Bammeke, F., Liddy, C., Hogel, M., Archibald, D., Chaar, Z. \& MacLaren, R. (2015). Family medicine residents' barriers to conducting scholarly work. Canadian Family Physician, 61(9), pp 780-787.

Begley, C., McCarron, M., Huntley-Moore, S., Condell, S. \& Higgins, A. (2014). Successful research capacity building in academic nursing and midwifery in Ireland: An exemplar. Nurse Education Today, 34(5), pp 754-760.

Boyd, P., Smith, C., Lee, S., MacDonald, I., Bunyan, P., Peel, J. \& Powell-James, A. (2009). Becoming a Health Profession Educator in a University: the experiences of recently-appointed lecturers in Nursing, Midwifery and the Allied Health Professions. This project was supported by funding from the Health Science and Practice Subject Centre of the Higher Education Academy in collaboration with ESCalate, the Education Subject Centre, University of Cumbria, UK.

Choo, T.L. \& Pung, C.M. (2017). Attitudes, barriers and facilitators to the conduct of research in government hospitals: A cross-sectional study among specialists in government hospitals, Northern states of Malaysia. Medical Journal of Malaysia, 72(1), pp 26-31. 
Chomsky-Higgins, K., Miclau, T.A., Mackechnie, M.C., Aguilar, D., Avila, J.R., dos Reis, F.B., Balmaseda, R., Barquet, A., Ceballos, A., Contreras, F., Escalante, I., Elias, N., Vincenti, S.I., Lozano, C., Medina, F., Merchan, G., Segovia, J., Guerado, E., Quintero, J.E., Morshed, S., Bhandari, M. \& Miclau, T. (2017). Barriers to clinical research in Latin America. Frontiers in Public Health, 5: 57.

Creswell, J.W. (2009). Research design: Qualitative, quantitative, and mixed methods approaches, London: Sage publications.

Durning, S.J., Cation, L.J., Ender, P.T. \& Gutierrez-Nunez, J.J. (2004). A resident research director can improve internal medicine resident research productivity. Teaching and Learning in Medicine, 16(3), pp 279-283.

Elo, S. \& Kyngäs, H. (2008). The qualitative content analysis process. Journal of Advanced Nursing, 62(1), pp 107-115.

Farzaneh, E., Amani, F., Taleghani, Y.M., Fathi, A., Kahnamouei-aghdam, F. \& Fatthzadeh-Ardalani, G. (2017). Research barriers from the viewpoint of faculty members and students of Ardabil University of Medical Sciences, Iran, 2014. International Journal of Research in Medical Sciences, 4(6), pp 1926-1932.

Frantz, J.M. (2012). A faculty development strategy among academics to promote the scholarship of research. African Journal of Health Professions Education, 4(2), pp 118-122.

Gurunathan, U., Berry, K. \& Way, M. (2016). Intentions and barriers to research activities among Australian and New Zealand Anaesthetists: A survey. Anaesthesia and Intensive Care, 44(1), pp 111-118.

Hames, K., Patlas, M. \& Duszak, R. (20180. Barriers to Resident Research in Radiology: A Canadian Perspective. Canadian Association of Radiologists Journal, 69(3), pp 260-265.

Hardman, R.L., Rahal, A., Walker, J., Tavakoli, S., Rodriguez, P., Vargas, D., Suri, R., Garcia-Rojas, X., Jung, A.J., Fullerton, G.D. \& Clarke, G. (2013). Combined radiology residency-PhD program: 10-year review of program results. Journal of the American College of Radiology, 10(10), pp 738-741.

Hemsley-Brown, J. \& Oplatka, I. (2005). Bridging the research-practice gap: barriers and facilitators to research use among school principals from England and Israel. International Journal of Public Sector Management, 18(5), pp 424-446.

Hiep, P.H. (2006). Researching the research culture in English language education in Vietnam. TESL-EJ, 10(2), pp1-20.

Jahan, F., Al Maqbali, A., Siddiqui, M.A. \& Al Zadjali, N.M. (2015). Attitude and Barrier towards Research amongst Health Care Professionals Working in Primary Care Service of Oman. Journal of Health Education Research \& Development, 3(3), pp 1-5.

Jerzak, K. \& Haider, S. (2015). Scholarly success among internal medicine residents in Canada. Canadian Journal of General Internal Medicine, 10(3), pp 33-37.

Khazanah Research Institute (2018). The State of Households 2018: Different Realities. Khazanah Research Institute, pp 5. Retrieved from: http://www.krinstitute.org/assets/contentMS/img/template/editor/FullReport_KRI_ SOH_2018.pdf

Kho, G-W.K. \& Ling, Y-L. (2017). A Study of Perception and Capability to Undertake Action Research Among Lecturers at a Polytechnic in Sarawak. Teacher Education and Curriculum Studies, 2(4), pp 41-46.

Li, B., Millwater, J. \& Hudson, P. (2008). Building Research Capacity: Changing Roles of Universities and Academics in Australian Association of Research in Education (AARE) Conference 2008, Brisbane, Qld., Australian Association for Research in Education (AARE). Retrieved from: http://www.aare.edu.au/08pap/bai08493.pdf

Mok, P.S., Probyn, L. \& Finlay, K. (2016). Factors influencing radiology residents' fellowship training and practice preferences in Canada. Canadian Association of Radiologists Journal, 67(2), pp 99-104. 
Rothberg, M.B., Kleppel, R., Friderici, J.L. \& Hinchey, K. (2014). Implementing a resident research program to overcome barriers to resident research. Academic Medicine, 89(8), pp 1133-1139.

Sabzwari, S., Kauser, S. \& Khuwaja, A.K. (2009). Experiences, Attitudes and Barriers Towards Research Amongst Junior Faculty of Pakistani Medical Universities. BMC medical education, 9:68.

Silcox, L.C., Ashbury, T.L., VanDenKerkhof, E.G. \& Milne, B. (2006). Residents' and program directors' attitudes toward research during anesthesiology training: a Canadian perspective. Anesthesia \& Analgesia, 102(3), pp 859-864.

Smith, C. \& Boyd, P. (2012). Becoming an academic: The reconstruction of identity by recently appointed lecturers in nursing, midwifery and the allied health professions. Innovations in Education and Teaching International, 49(1), pp 63-72. 